Edited by:

David M. Diamond, University of South

Florida, USA

Reviewed by:

Phillip R. Zoladz, Ohio Northern

University, USA

Victoria Risbrough, University of

California at San Diego, USA

*Correspondence:

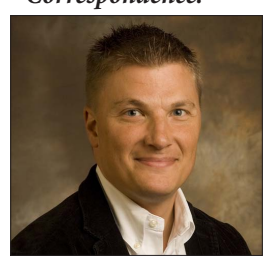

Seth Davin Norrholm is a translational neuroscientist who studies the acquisition and extinction of learned fear in traumatized combat and civilian populations. A primary objective of his work is to develop "bench-to-bedside" clinical research methods to inform interventions for post-traumatic stress disorder (PTSD). His work has been supported by the Brain and Behavior Foundation and the Congressionally Directed Medical Research Program through the Department of Defense (CDMRP/DoD). Dr. Norrholm is a member of several journal Editorial boards including the Frontiers publishing group. snorrho@emory.edu

\section{Conditioned fear associated phenotypes as robust, translational indices of trauma-, stressor-, and anxiety-related behaviors}

\author{
Maria Anne Briscione ${ }^{1,2}$, Tanja Jovanovic ${ }^{2}$ and Seth Davin Norrholm ${ }^{1,2^{*}}$ \\ Trauma Recovery Program, Mental Health Service Line, Atlanta Veterans Affairs Medical Center, Decatur, GA, USA \\ 2 Department of Psychiatry and Behavioral Sciences, Emory University School of Medicine, Atlanta, GA, USA
}

Post-traumatic stress disorder (PTSD) is a heterogeneous disorder that affects individuals exposed to trauma (e.g., combat, interpersonal violence, and natural disasters). It is characterized by hyperarousal, intrusive reminders of the trauma, avoidance of trauma-related cues, and negative cognition and mood. This heterogeneity indicates the presence of multiple neurobiological mechanisms underlying the development and maintenance of PTSD. Fear conditioning is a robust, translational experimental paradigm that can be employed to elucidate these mechanisms by allowing for the study of fear-related dimensions of PTSD (e.g., fear extinction, fear inhibition, and generalization of fear) across multiple units of analysis. Fear conditioning experiments have identified varying trajectories of the dimensions described, highlighting exciting new avenues of targeted, focused study. Additionally, fear conditioning studies provide a translational platform to develop novel interventions. The current review highlights the versatility of fear conditioning paradigms, the implications for pharmacological and non-pharmacological treatments, the robustness of these paradigms to span an array of neuroscientific measures (e.g., genetic studies), and finally the need to understand the boundary conditions under which these paradigms are effective. Further understanding these paradigms will ultimately allow for optimization of fear conditioning paradigms, a necessary step towards the advancement of PTSD treatment methods.

Keywords: fear learning, startle reaction, anxiety disorders, traumatology, translational medical research

\section{INTRODUCTION}

Post-traumatic stress disorder (PTSD) affects $8 \%$ of the general population and occurs at a much higher percentage in populations at risk of experiencing trauma; this includes military personnel and individuals living in low-socioeconomic urban environments $(1,2)$. The incidence of combat-related PTSD is expected to rise given the number of veterans returning from theaters of conflict in Iraq and Afghanistan. According to early reports, approximately 20\% of Operation Iraqi Freedom and Operation Enduring Freedom (OEF and OIF, respectively) veterans presented with PTSD symptoms upon their return from combat (3). While these recent conflicts have generated new cases of PTSD, there remain a significant number of Vietnam veterans who have been experiencing persistent PTSD symptoms for as long as 40 years (4). Based on earlier work from our group, PTSD is equally as pervasive in low-socioeconomic urban environments including Atlanta, GA, USA $(5,6)$.

Post-traumatic stress disorder is the fifth most common psychiatric diagnosis and is not limited to the aforementioned groups $(2,7)$. Unfortunately, many of the traumatic events that precede the development of PTSD are not preventable, and we can expect new cases to develop as a result of 
widespread trauma across military and civilian populations. For example, returning veterans from the most recent combat theaters have been exposed to the unpredictable nature of urban warfare, which includes suicide bombings and improvised explosive devices (IEDs). In civilian populations from low-socioeconomic urban environments, there is risk of interpersonal violence and sexual assault. Further, victims of natural disasters, who can number in the thousands, can develop PTSD symptoms in the wake of unforeseen devastation to person and property (8). It is becoming increasingly clear that one's individual risk for developing PTSD following exposure to a traumatic event is influenced by both intrinsic (e.g., genomic) and extrinsic (e.g., social support network) factors.

Post-traumatic stress disorder is a heterogeneous disorder in which symptoms span four primary symptom clusters according to the recent Diagnostic and Statistical Manual of Mental Disorders, $5^{\text {th }}$ edition [DSM-5; (9)]. The DSM-5 PTSD symptoms clusters include: (1) re-experiencing, such as flashbacks and recurrent nightmares, (2) avoidance, which includes circumventing thoughts and feelings associated with the traumatic event, (3) negative cognitions and mood, which encompasses detachment from others and a loss of interest in activities, and (4) hyperarousal, which can manifest itself as difficulty sleeping and feeling overly alert.

This heterogeneity implies the involvement of multiple neurobiological mechanisms, which underlie the development and maintenance of PTSD [for a comprehensive review, see (10)]. The classification of PTSD symptoms according to clusters provides some utility in the clinic; however, there is a movement in the field to adopt a new strategy focused on the study of neurobiological mechanisms that "cut across" mental disorders and underlie multiple psychiatric disease states [Research Domain Criteria; RDoC; (11)].A central tenet of the RDoC framework is "classifying psychopathology based on dimensions of observable behavioral and neurobiological measures." RDoC focuses on several different systems, including the Negative Valence System; the construct matrix for this system includes acute threat or fear, which can be measured across several units of analysis. The focus of this review is on fear-conditioning studies that are defined under this construct.

Fear conditioning paradigms provide a compelling translational platform for investigating the neural underpinnings of traumaand stressor-related disorders, such as PTSD and anxiety disor-

\section{KEY CONCEPT 1 | Fear conditioning}

A paradigm where a neutral stimuli is paired with unpleasant/aversive event to conceptualize and objectively study a traumatic experience according to the principles of Pavlovian conditioning such that the unconditioned fear responses are similar to those experienced at the time of trauma that become elicited by stimuli similar to those present at the time of the trauma.

ders such as panic and specific phobia. Interestingly, the DSM-5 no longer includes Criterion A2, or the presence of fear, helplessness, or horror in response to a traumatic event, in the diagnostic criteria that must be endorsed for a clinical diagnosis of PTSD; however, dysregulation of fear conditioning-related phenotypes remains a central feature of this disorder (12). As described in a recent review by Weston (13), neural circuitry that includes the amygdaloid complex can be associated with at least 14 symptoms of PTSD and, as such, there remains compelling interest in developing and utilizing translational paradigms that index these circuits, including fear inhibition (14), fear extinction (15), and stimulus generalization (16). In translational experimental paradigms, the general term extinction can refer to the learning process that occurs

\section{KEY CONCEPT 2 | Fear inhibition}

Fear inhibition refers to the ability to inhibit a fear response in the presence of a safety signal and can be observed experimentally when a previously reinforced CS+ is presented in compound with a neutral, safe stimulus.

\section{KEY CONCEPT 3 | Fear extinction}

Fear extinction is a form of new learning that occurs when the previously reinforced CS+ is repeatedly presented in the absence of the aversive US. It is a translational tool, such that it is experimentally homologous to exposure therapy. Dysregulated fear extinction in patients with PTSD appears to manifest itself in at least three ways that may not be mutually exclusive.

during the non-reinforced presentation of a previously reinforced CS (termed extinction training) as well as the retention of extinction learning after a period of time has elapsed since extinction training [termed extinction recall; (17)].

\section{FEAR CONDITIONING}

Self-report measures of PTSD can often be subjective and unreliable. The high comorbidity of PTSD and depression highlights this problem; specifically, measures of PTSD and depression [as indexed by the Clinician Administered PTSD Scale (CAPS) and the Beck Depression Index (BDI), respectively) may reflect overlapping symptoms of negative affect $(18,19)$. Similarly, the symptom dimensions used for a diagnosis may reflect complex sequelae resulting from an overlap in symptom presentation of multiple disorders (20). Fear conditioning allows the use of quantitative objective measures to identify and differentiate components of PTSD, most notably those related to the dysregulation of fear processing.

Fear conditioning utilizes Pavlovian conditioning and involves the association of previously neutral stimuli with unpleasant or aversive events. Experimentally, a neutral stimulus (i.e., shape or sound) is spatially or temporally paired with an aversive unconditioned stimulus (US), typically a blast of air or a mild electric shock. Previously, the neutral stimulus comes to evoke the same response as the US, even in the absence of the US, and is termed the reinforced conditioned stimulus [CS+, Ref. (21)]. When conceptualizing a traumatic experience according to the principles of fear conditioning, unconditioned fear responses (UCR) similar to those experienced at the time of trauma can subsequently be elicited by stimuli (termed conditioned stimuli or CSs) similar to those present at the time of the trauma (e.g., sights, sounds, smells, context).

Conditioned fear responses can be quantified experimentally in a variety of ways. Fear potentiation of the acoustic startle response is a commonly employed translational methodology for indexing learned fear. The acoustic startle response ("startle") is characterized by an integrative reflex contraction of the skeletal musculature in response to a strong stimulus (e.g., loud noise) and is an ideal model for studying fear conditioning since the amygdala is directly inter-connected with the startle circuit (22-24). Fear-potentiated startle is defined as an increase in the magnitude of the startle response when it is elicited in the presence of a CS+ that has been repeatedly paired with an aversive US; this methodology inherently includes a within-subject non-zero baseline measure of an 


\section{KEY CONCEPT 4 | Fear-potentiated startle}

Conditioned fear responses can be quantified experimentally in a variety of ways and fear potentiation of the acoustic startle response is a commonly employed translational methodology for quantitatively indexing learned fear across mammalian species. It refers to the relative increase from baseline startle in the presence of a fearful stimulus.

individual's acoustic startle response $(25,26)$. Fear-potentiated startle is observed across species and is ideal for studying translational models of fear-related phenotypes (27).

In typical human fear-conditioning approaches, an acquisition phase is presented in which a previously neutral CS is paired with an aversive US such that the CS comes to predict the US and, as such, a fear response of interest is elicited (potentiation of startle as compared to baseline or increase in skin conductance in the presence of the CS+ as opposed to a non-reinforced CS-). In addition, many paradigms will include a real-time measure of US-expectancy such that participants report their prediction of the presence or absence of a CS on a trial-by-trial basis. This allows investigators to determine whether participants can accurately discriminate between danger cues (CS+) and safety cues (CS). These measures further allow investigators to discern a psychophysiological, but not a cognitive, response consistent with a dysregulated system. For example, PTSD patients have shown increased fear responses to cues that they subjectively report as safe (28).

Following an Acquisition phase, translational studies of conditioned fear will often employ one of three procedures for measuring the expression and/or inhibition of the newly acquired fear: (1) fear extinction, (2) fear inhibition, or (3) generalization of fear. Alterations in fear extinction, fear inhibition, and stimulus

\section{KEY CONCEPT 5 | Generalization of fear}

Generalization of fear or stimulus generalization refers to the ability to discern fearful and safety cues. Generalization is a measure of the degree to which a conditioned fear response is expressed in the presence of generalization stimuli that vary incrementally from an initially presented CS+.

generalization have all been reported, using fear-potentiated startle methods, in populations with trauma- and stressor-related as well as anxiety disorders [see Figure 1; $(16,29-31)$ ]. Fear extinction is a form of new learning that occurs when the previously reinforced CS+ is repeatedly presented in the absence of the aversive US [e.g., Ref. (17)]. Despite some recent reports to the contrary

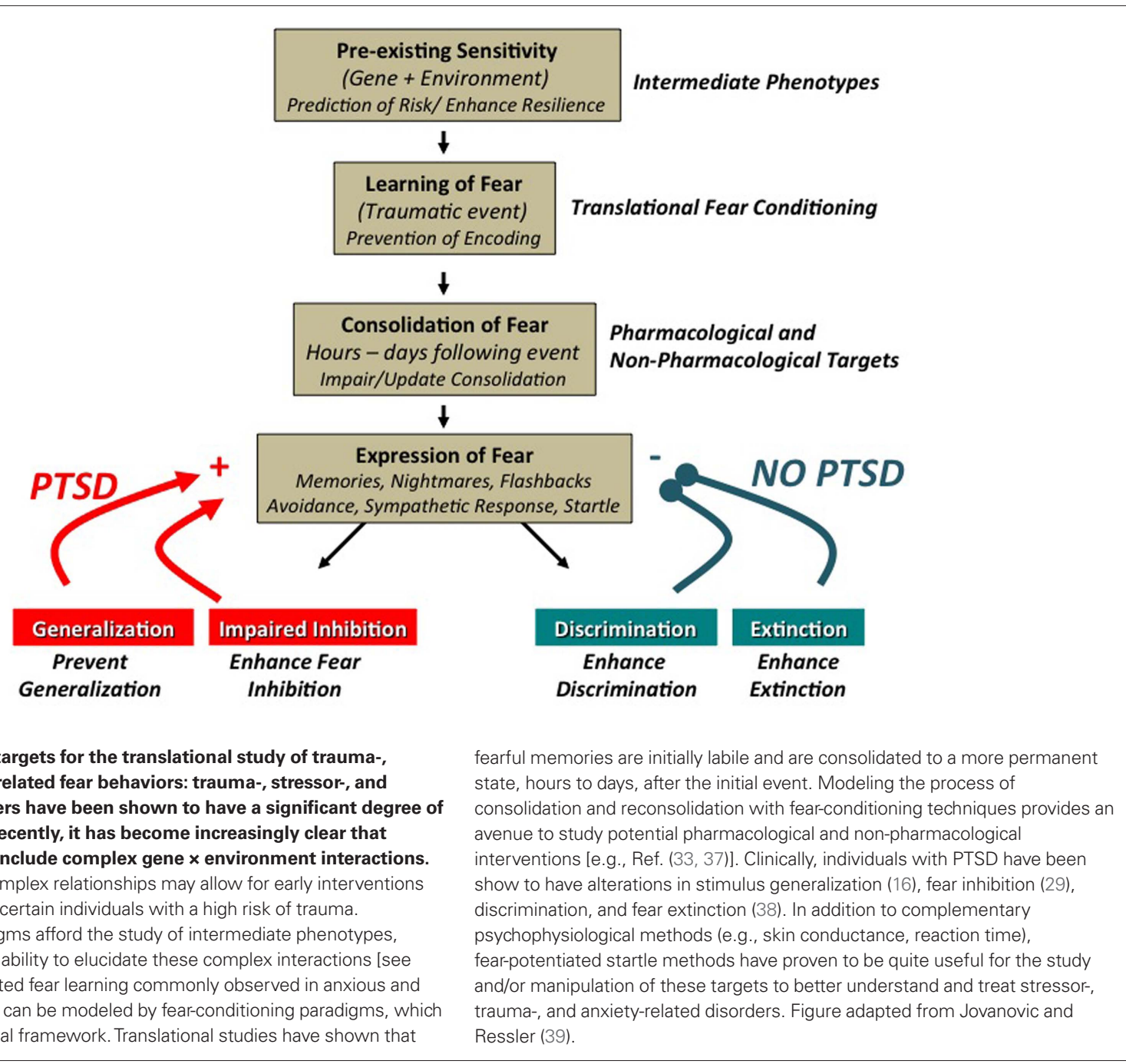


[e.g., Ref. $(32,33)]$, the predominant understanding is that the original fear memory (CS-US association) is not erased, but competes with new extinction learning, and can be accessed through the processes of spontaneous recovery (following the passage of time), renewal (shift in context), or reinstatement (the unsignaled presentation of the aversive US). Fear inhibition has traditionally been observed when a previously reinforced CS+ (termed cue A) is presented in compound with a neutral stimulus [termed the $\mathrm{AB}$ compound; (34)]. More recent studies of fear inhibition have used compound stimuli in which one compound is reinforced (termed $\mathrm{AX}+$ ), another is non-reinforced (termed $\mathrm{BX}-$ ) during acquisition. Fear inhibition is then measured as the transfer of the inhibitory (safe) properties of stimulus B onto stimulus A [via presentation of an AB compound; $(29,35)]$. Generalization of fear (or stimulus generalization) has been more widely studied recently and is a measure of the degree to which a conditioned fear response is expressed in the presence of generalization stimuli (GSs) that vary incrementally from an initially presented CS+ [e.g., concentric rings of increasing or decreasing diameter from the original CS+; (27); or morphed faces of which one is the CS+; (31)].

Fear extinction, as a translational tool, is an important area of study due to its relevance to the limbic neural circuitry believed to underlie fear psychopathology and also due to its role as an experimental homolog to exposure therapy, which is currently recognized as the most effective treatment for fear and anxiety. Dysregulated fear extinction in patients with PTSD symptoms appears to manifest itself in at least three ways that may not be mutually exclusive: over-expression of acquired fear, impaired within-session extinction learning (decrease in fear observed during the experimental session), and impaired between-session extinction retention (decrease in fear from one session to the next, which reflects memory consolidation processes). With regard to over-expression of acquired fear, previous work from our lab (15) suggests that the early phase of within-session extinction learning involves persistent excitation, as it is predicted by the level of fear expression to the CS+ (i.e., the danger signal) at the end of acquisition. For example, our group showed heightened levels of fear during early extinction in a previously traumatized population with PTSD consisting of primarily African-American women living in a low-socioeconomic urban environment; we termed this pattern of extinction learning as being indicative of "fear load," or the over-expression of fear during early extinction. High levels of conditioned fear remaining during late extinction are related to impaired inhibition, as it is best predicted by responses to the CS- (i.e., safety signal) at the end of acquisition (15). This is based on the notion that extinction learning is a form of fear inhibition. As an example, we previously showed that a predominately male population of combat veterans with PTSD did not show "fear load," but rather impaired within-session extinction learning characterized by a "persistence of fear" (40). Lastly, work by Milad and others $(41,42)$ demonstrated that individuals with PTSD showed a reduced ability to recall extinction learning when tested $24 \mathrm{~h}$ after within-session extinction learning had occurred. The presence of divergent extinction trajectories as described above represents an exciting new avenue of study and has recently been introduced in the rodent literature (43), which may be analogous to heterogeneous responses to trauma in PTSD (44).

\section{UNITS OF ANALYSIS}

While PTSD symptom clusters provide a useful set of diagnostic criteria and could be used to discern the most effective treatment [for a comprehensive review, see Ref. (10)], they represent broad categories of behavior and do not easily reflect common underlying mechanisms. Using the RDoC approach, fear-conditioning studies can identify intermediate phenotypes, which represent specific components of a disorder and allow for a more direct examination of brain-behavior relationships. We define intermediate phenotypes as observable units that are (1) related to the underlying neurobiology of a disorder, (2) related to clinical symptoms of the disorder, and (3) are ideally possible to model in animal studies affording a translational approach. Unlike an endophenotype, an intermediate phenotype does not necessarily require heritability. An intermediate phenotype can be assessed with different units of analysis, including molecular, neural circuitry, physiology, behavior, and self-reports such as those listed in the RDoC matrix (http://www. nimh.nih.gov/research-priorities/rdoc/nimh-research-domaincriteria-rdoc.shtml). For the purpose of this review, we focused on physiological units of analysis, including fear-potentiated startle and skin conductance response as fear conditioning-related intermediate phenotypes.

KEY CONCEPT 6 | Fear conditioning-related intermediate phenotypes Observable units that are (1) related to the underlying neurobiology of a disorder, (2) related to clinical symptoms of the disorder, and (3) are ideally possible to model in animal studies affording a translational approach.

Numerous translational studies have employed fear-conditioning paradigms to better identify more basic dimensions and phenotypes associated within these diagnostic criteria. For example, previous work has shown that subjects with high hyperarousal symptoms show the greatest difficulty inhibiting a fear response to safety cues (45). In addition, during extinction learning, increased fearpotentiated startle was associated with re-experiencing symptoms of PTSD (15). The same study showed a more robust fear response to both the CS+ (danger cue) and the CS- (safety cue) during acquisition that was associated with higher re-experiencing and hyperarousal symptoms.

Research has indicated that fear conditioning and cognitive biases share a common underlying neural mechanism, amygdalaprefrontal circuitry (46). One aspect of cognitive bias, attention bias, or the facilitated orientation toward, or avoidance of, specific cues, has been shown to be a useful index of anxiety-related disorders (46). This proposed connection between attention bias and fear conditioning has been explicitly examined. Fani et al. (47) showed that attention bias toward threat is associated with over-expression of fear during early extinction, referred to as "fear load." This study provides further evidence of the utility of intermediate phenotypes to enhance our understanding of underlying neural circuitry and corresponding behavioral responses.

Further, PTSD has long been associated with intrinsic [e.g., age and gender $(48,49)]$, environmental (e.g., exposure to trauma, rearing environment, degree of social support), and genetic factors (5052). The dysregulated fear learning observed in subjects with PTSD likely reflects the complexity of these interactions. Specifically, several candidate gene studies have identified genetic differences and specific gene pathways involved in PTSD [for a review, see (53)]. 
When conducting both candidate gene studies and genome-wide association studies (GWAS), it is common for the resulting genetic findings to associate with many disorders or only to distinct phenotypes of broader disorders, a central concern outlined in RDoC. It is useful to instead study intermediate phenotypes or specific components of disorders. For example, we recently showed that increased "fear load," as measured by fear-potentiated startle was related to the catechol-O-methyl-transferase (COMT) Val66Met polymorphism and a diagnosis of PTSD (36). More recently, GWAS data, which is obtained when expression levels of the whole genome are analyzed in the context of PTSD, have been used to identify novel gene pathways involved in the mechanisms underlying complex disorders such as PTSD [see Ref. (54) for a review]. The use of these intermediate phenotypes not only enhances the ability to identify complex gene interactions but also allows for these gene pathways to be more readily studied. Fear conditioning provides a potential framework for studying these phenotypes [see Ref. $(55,56)]$.

\section{VERSATILITY}

Fear-potentiated startle can be used in several mammalian species (57); however, in animal models the CSs are typically auditory, whereas visual CSs are used in human studies. In order to bridge this gap, Norrholm and colleagues examined the use of auditory and visual CSs in fear conditioning of healthy participants (58). Briefly, healthy participants acquired fear to auditory stimuli comparable to the participants who were fear conditioned with visual stimuli. Both groups also discriminated between the CS+ and CS-; however, the auditory group exhibited discrimination on blocks 1, 2, and 3 of fear acquisition, while the visual CS+ group exhibited discrimination on blocks 2 and 3 of fear acquisition. Ten minutes after this initial assessment, these groups were shown to also extinguish fear; however, the auditory group displayed a steeper slope of extinction, due in part to an initial increase in fear during extinction, than the visual group. Twenty-four hours later an extinction test was performed. This test showed that spontaneous recovery occurred in both groups and US-expectancy ratings increased in both groups regardless of modality as well (58). The advantage of this versatility is that it can be used in patients with visual impairment with equivalent results and also lends itself to the use of "cross-over" longitudinal studies in which practice effects can be minimized.

\section{TREATMENT}

Not surprisingly, treatment approaches aimed at reducing the fear-related symptoms of PTSD (e.g., re-experiencing and intrusive memories) have focused on the disruption of fear memory consolidation/reconsolidation, facilitation of extinction learning, and the prevention of the return of fear. Several recent translational studies have explored both pharmacological as well as non-pharmacological means of enhancing extinction of fear and preventing its re-emergence. Memory consolidation refers to the process of

\section{KEY CONCEPT 7 | Memory consolidation}

Memory consolidation is the process of transforming a memory (e.g., fear memory) from a labile state immediately after acquisition to a more permanent state that occurs after sometime. This process has been the target for nonpharmacological attempts to facilitate fear extinction and prevent the return of conditioned fear in humans. transforming a memory (e.g., fear memory) from a labile state immediately after acquisition to a more permanent state that occurs after some time [believed to be $6 \mathrm{~h}$ or more post-acquisition; e.g., Ref. (59)]. Clinically speaking, memory consolidation first occurs at the time at which the traumatic event occurs. Many cellular processes have been described as underlying the neural mechanisms of consolidation, including the activation of $\beta$-adrenergic receptors in amygdala; however, administration of the $\beta$-adrenergic receptor antagonist, propranolol, while initially promising, has not shown any significant effects regarding memory consolidation in large scale studies $(60,61)$. Morphine has also been studied as a possible intervention of fear memory consolidation; however, it is not clear whether morphine's analgesic properties act to reduce the potency of the CS+ or are acting through a separate mechanism $(61,62)$.

With regard to the facilitation of extinction learning, a potential avenue was revealed by Davis and colleagues who reported that learning to extinguish conditioned fear was dependent on $N$-methyl-D-aspartate (NMDA) glutamate receptors in limbic regions including the amygdala (63). A decade later, Walker et al. (64) found that D-cycloserine (DCS), an NMDA receptor partial agonist, facilitated extinction learning in rats; a finding that was later replicated by several other groups employing multiple types of fear learning paradigms in rodents [e.g., Ref. (65)] but not replicated using skin conductance and expectancy ratings in humans (66). Shortly thereafter, several groups reported that DCS administration before or after exposure therapy, a form of treatment based on the principles of fear extinction learning, was effective in alleviating the symptoms of acrophobia (67), panic disorder (68), social anxiety disorder $(69,70)$, and obsessive-compulsive disorder (71-73).

At present, the effectiveness of DCS in facilitating exposure therapy (i.e., extinction learning) for PTSD is unclear due to mixed reports in the extant literature. DCS has been shown to be effective under specific clinical conditions. For example, de Kleine and colleagues reported increased improvement in the symptom ratings of patients who were administered DCS and initially reported more severe symptom severity (74). Initial reports by Litz et al. (75) suggested that DCS + exposure therapy was not as effective as placebo + exposure in a population of combat veterans with PTSD (75) However, more recent reports from the latter group suggest that the effectiveness of DCS as an adjunct therapy may be related to the degree of fear reduction observed during individual exposure therapy sessions $(76,77)$ Additionally, a recent study used DCS in addition to virtual reality exposure therapy in patients suffering PTSD as a result of the $9 / 11$ attacks and found significant clinical advantages of DCS compared to placebo (78). Specifically, when DCS was administered prior to virtual reality exposure therapy subjects showed earlier, enhanced symptom reduction and greater PTSD remission rates (78). Finally, trauma imagery-potentiated startle responses in recently returned combat veterans from Iraq and Afghanistan were significantly reduced in individuals who previously received DCS before each of five sessions of virtual reality exposure therapy for PTSD (38).

In addition to agents that act on glutamatergic systems, other pharmacological approaches have been examined as possible therapies for fear- and anxiety-related disorders because of their potential to facilitate extinction learning and/or prevent the return of fear. 
Pre-clinical rodent studies have shown that monoaminergic specific antidepressants such as venlafaxine (serotonin-norepinephrine reuptake inhibitor; SNRI) and fluoxetine (serotonin specific reuptake inhibitor; SSRI) can facilitate between-session extinction $(79,80)$ and prevent reinstatement of conditioned fear $(80,81)$. Although the use of antidepressants has not been widely studied in extinction of fear-potentiated startle studies, there is some evidence from skin conductance-based investigations suggesting a facilitatory role of these drugs in fear extinction learning (82).

The endocannabinoid system has also been implicated in conditioned fear extinction and represents an additional area of exploration for facilitating extinction and prevention of fear return. Chhatwal et al. (83) showed that enhanced cannabinoid receptor CB1 activation (via administration of AM404, an agent that prevents endocannabinoid degradation and reuptake) facilitated within-session and between-session extinction of fear-potentiated startle as well as reinstatement in mice (83). This work was furthered by Gunduz-Cinar et al. $(84,85)$ who showed that inhibition of fatty acid amide hydrolase (FAAH), the enzyme that catabolizes the endogenous cannabinoid anandamide, enhances extinction learning in rodents and could represent a risk variant for stressorrelated psychiatric disorders $(84,85)$.

New avenues for exploration continue to emerge and represent expanding opportunities to apply the fear conditioning and extinction procedures described herein. For example, Acheson and colleagues showed that the extinction of fear-potentiated startle in healthy humans could be enhanced with the intranasal administration of oxytocin (86). In addition, recent evidence from mouse studies implicates the renin-angiotensin system in the regulation of fear and anxiety responses as angiotensin receptor AT1 antagonism with the anti-hypertension drug losartan has been shown to enhance fear extinction learning [extinction recall; (87)].

Non-pharmacological attempts to facilitate fear extinction and prevent the return of conditioned fear in humans have focused on the disruption of the original fear memory trace (CS-US association) by interfering with consolidation or reconsolidation following retrieval of a previously stored fear memory. One approach for disrupting consolidation of fear memories (CS-US association) that has been explored is immediate versus delayed extinction training. Myers et al. (32) showed that extinction training initiated immediately after $(10 \mathrm{~min})$ fear acquisition prevented the return of learned fear via reinstatement, renewal, or spontaneous recovery. It was believed that extinction training, while the CS-US association was still labile, provided updated information regarding the association between the CS and US before the original association had been consolidated. This finding was not well replicated in rodents [see Ref. $(88,89)$ ] and was only weakly observed in humans [see Ref. (90)].

More recently, Monfils et al. (33) developed a paradigm termed retrieval + extinction in which a single CS+ trial is presented without the US to open a reconsolidation window in which the original fear memory is returned to a labile state. Extinction training is then administered within this reconsolidation window (e.g., $1 \mathrm{~h}$ ) in an effort to disrupt reconsolidation of the original fear memory. Monfils and colleagues showed that retrieval + extinction effectively attenuated the return of fear through renewal or reinstatement (33). Following this work, Schiller et al. (59), using skin conductance measures, showed that retrieval + extinction (with 10 min but not $6 \mathrm{~h}$ between sessions) attenuated spontaneous recovery and reinstatement of fear in human subjects, an effect that was evident a year after the original acquisition of fear.

Similar to the aforementioned studies using immediate versus delayed extinction, attempts to replicate the retrieval + extinction effects reported by the Monfils et al. (33) and Schiller et al. (59) groups have yielded mixed results in human studies. It has become apparent that there are specific boundary conditions under which

\section{KEY CONCEPT 8 | Boundary conditions}

Boundary conditions are the conditions under which fear conditioning paradigms (e.g., retrieval + extinction) are effective. For example, these conditions include, but are not limited to, the type of psychophysiological measure employed (e.g., skin conductance), the schedule of reinforcement used during acquisition, and the strength of the fear memory following acquisition.

retrieval + extinction is effective. These conditions include, but are not limited to, the type of psychophysiological measure employed, the schedule of reinforcement used during acquisition, the fearrelevancy of the conditioned stimuli presented, the strength of the fear memory following acquisition, and the presence or absence of on-line measures of expectancy or fear ratings [see Ref. (37, 91-93)].

\section{CONCLUSION}

The utility of fear conditioning-related intermediate phenotypes can be observed across multiple units of analysis. Understanding these phenotypes (i.e., fear inhibition, high fear load, fear generalization, etc.) and the divergent manifestations of these responses in the context of a broader etiology (i.e., genetic, behavioral, symptomatic, and clinical studies) may lead to more effective treatment and preventative strategies for PTSD and other trauma-, stressor-, and anxiety-related disorders.

While the present review summarized the current progress of interfacing fear conditioning-related intermediate phenotypes and genetic (54), behavioral (47), symptomatic $(15,45)$, and clinical studies (78), further characterization of these intermediate phenotypes will enhance the utility of fear-conditioning studies. For example, PTSD is known to affect women more commonly than men $(1,94)$, and fear-conditioning paradigms are useful for characterizing the sex differences underlying different neuronal, endocrine, and behavioral responses to trauma and other stressors. For example, a polymorphism in the pituitary adenylate cyclaseactivating polypeptide receptor gene (ADCYAP1R1) is associated with decreased fear discrimination in females but not males (95). These findings illustrate the association between genetic risk, brainbehavior interactions, and intermediate phenotypes.

Ultimately, potential breakthroughs will increase the utility of fear-conditioning studies as a translational platform for studying the intermediate phenotypes underlying dysregulated fear learning, a central tenant of trauma-, stressor-, and anxiety-related disorders. This is especially useful due to the high comorbidity of PTSD and other disorders including depression and substance abuse. By identifying these intermediate phenotypes, we can create specific testable measures, which can then be used to examine the effectiveness of treatment interventions. 


\section{ACKNOWLEDGMENTS}

This work was funded in part by the Brain and Behavior Foundation (formerly NARSAD; Seth Davin Norrholm and Tanja Jovanovic), the Department of Defense (DOD)/Congressionally Directed Medical Research Program (CDMRP, Award \# W81XWH-08-2-0170) (PI, Seth Davin Norrholm), the Emory University Research Committee, a PHS Grant (UL1 RR025008) from the Clinical and Translational Science Award program, National Institutes of Health, National Center for Research Resources (Seth Davin Norrholm). We thank Jasper A. J. Smits for his assistance in the preparation of this manuscript.

\section{REFERENCES}

1. Kessler RC, Sonnega A, Bromet E, Hughes M, Nelson CB. Posttraumatic stress disorder in the National Comorbidity Survey. Arch Gen Psychiatry (1995) 52:1048-60. doi: 10.1001/archpsyc. 1995.03950240066012

2. Keane T, Marx B, Sloan D. Post-Traumatic Stress Disorder: Definition, Prevalence, and Risk Factors. New York: Humana (2009).

3. Hoge CW, Castro CA, Messer SC, Mcgurk D, Cotting DI, Koffman RL. Combat duty in Iraq and Afghanistan, mental health problems, and barriers to care. NEngl J Med (2004) 351:13-22. doi: 10.1056/NEJMoa040603

4. Kulka R, Schlenger W, Fairbanks J, Hough R, Jordan B, Marmar C, et al. Trauma and the Vietnam War Generation: Report of Findings from the National Vietnam Veterans Readjustment Study. New York, NY: Brunner/Mazel, Inc (1990).

5. Schwartz AC, Bradley RL, Sexton M, Sherry A, Ressler KJ. Posttraumatic stress disorder among African Americans in an inner city mental health clinic. Psychiatr $\operatorname{Serv}$ (2005) 56:212-5. doi: 10.1176/appi.ps.56.2.212

6. Gillespie CF, Bradley B, Mercer K, Smith AK, Conneely K, Gapen M, et al. Trauma exposure and stress-related disorders in inner city primary care patients. Gen Hosp Psychiatry (2009) 31:505-14. doi: 10.1016/j.genhosppsych.2009.05.003

7. Kessler RC, Berglund P, Demler O, Jin R, Merikangas KR, Walters EE. Lifetime prevalence and age-of-onset distributions of DSM-IV disorders in the National Comorbidity Survey Replication. Arch Gen Psychiatry (2005) 62:593-602. doi: 10.1001/archpsyc.62.6.593

8. Galea S, Tracy M, Norris F, Coffey SF. Financial and social circumstances and the incidence and course of PTSD in Mississippi during the first two years after Hurricane Katrina. J Trauma Stress (2008) 21:357-68. doi: 10.1002/jts.20355

9. American Psychological Association. Diagnostic and Statistical Manual of Mental Disorders, Fifth Edition, DSM-5. Arlington, VA: APA (2013).

10. Norrholm SD, Jovanovic T. Tailoring therapeutic strategies for treating posttraumatic stress disorder symptom clusters. Neuropsychiatr Dis Treat (2010) 6:517-32. doi: 10.2147/NDT.S10951

11. Cuthbert BN. Research domain criteria: toward future psychiatric nosology. Asian J Psychiatr (2014) 7:4-5. doi: 10.1016/j.ajp.2013.12.007

12. Shin LM, Liberzon I. The neurocircuitry of fear, stress, and anxiety disorders. Neuropsychopharmacology (2010) 35:169-91. doi: 10.1038/npp.2009.83

13. Weston CS. Posttraumatic stress disorder: a theoretical model of the hyperarousal subtype. Front Psychiatry (2014) 5:37. doi: 10.3389/fpsyt.2014.00037

14. Jovanovic T, Norrholm SD, Fennell JE, Keyes M, Fiallos AM, Myers KM, et al. Posttraumatic stress disorder may be associated with impaired fear inhibition: relation to symptom severity. Psychiatry Res (2009) 167:151-60. doi: 10.1016/j. psychres.2007.12.014

15. Norrholm SD, Jovanovic T, Olin IW, Sands LA, Karapanou I, Bradley B, et al. Fear extinction in traumatized civilians with posttraumatic stress disorder: relation to symptom severity. Biol Psychiatry (2011) 69:556-63. doi: 10.1016/j. biopsych.2010.09.013

16. Lissek S, Rabin SJ, Mcdowell DJ, Dvir S, Bradford DE, Geraci M, et al. Impaired discriminative fear-conditioning resulting from elevated fear responding to learned safety cues among individuals with panic disorder. Behav Res Ther (2009) 47:111-8. doi: 10.1016/j.brat.2008.10.017

17. Myers KM, Davis M. Behavioral and neural analysis of extinction. Neuron (2002) 36:567-84. doi: 10.1016/S0896-6273(02)01064-4

18. Brown TA, Chorpita BF, Barlow DH. Structural relationships among dimensions of the DSM-IV anxiety and mood disorders and dimensions of negative affect, positive affect, and autonomic arousal. J Abnorm Psychol (1998) 107:179-92. doi: 10.1037/0021-843X.107.2.179
19. Bauer MR, Ruef AM, Pineles SL, Japuntich SJ, Macklin ML, Lasko NB, et al. Psychophysiological assessment of PTSD: a potential research domain criteria construct. Psychol Assess (2013) 25:1037-43. doi: 10.1037/a0033432

20. Franklin CL, Zimmerman M. Posttraumatic stress disorder and major depressive disorder: investigating the role of overlapping symptoms in diagnostic comorbidity. J Nerv Ment Dis (2001) 189:548-51. doi: 10.1097/00005053-200108000-00008

21. Davis M. The neurophysiological basis of acoustic startle modulation: research on fear motivation and sensory gating. In: Lang P, Simons R, Balaban M, editors. Attention and Orienting: Sensory and Motivational Processes. Mahwah, NJ: Lawrence Erlbaum Associates (1997). p. 69-96.

22. LeDoux JE, Iwata J, Cicchetti P, Reis DJ. Different projections of the central amygdaloid nucleus mediate autonomic and behavioral correlates of conditioned fear. J Neurosci (1988) 8:2517-29.

23. Davis M. The role of the amygdala in fear-potentiated startle: implications for animal models of anxiety. Trends Pharmacol Sci (1992) 13:35-41. doi: 10.1016/0165-6147(92)90014-W

24. Grillon C. Models and mechanisms of anxiety: evidence from startle studies. Psychopharmacology (Berl) (2008) 199:421-37. doi: 10.1007/s00213-007-1019-1

25. Davis M, Falls WA, Campeau S, Kim M. Fear-potentiated startle: a neural and pharmacological analysis. Behav Brain Res (1993) 58:175-98. doi: 10.1016/0166-4328(93)90102-V

26. Jovanovic T, Norrholm SD, Keyes M, Fiallos A, Jovanovic S, Myers $\mathrm{KM}$, et al. Contingency awareness and fear inhibition in a human fearpotentiated startle paradigm. Behav Neurosci (2006) 120:995-1004. doi: 10.1037/0735-7044.120.5.995

27. Lissek S, Biggs AL, Rabin SJ, Cornwell BR, Alvarez RP, Pine DS, et al. Generalization of conditioned fear-potentiated startle in humans: experimental validation and clinical relevance. Behav Res Ther (2008) 46:678-87. doi: 10.1016/j.brat.2008.02.005

28. Jovanovic T, Kazama A, Bachevalier J, Davis M. Impaired safety signal learning may be a biomarker of PTSD. Neuropharmacology (2012) 62:695-704. doi: 10.1016/j. neuropharm.2011.02.023

29. Jovanovic T, Keyes M, Fiallos A, Myers KM, Davis M, Duncan EJ. Fear potentiation and fear inhibition in a human fear-potentiated startle paradigm. Biol Psychiatry (2005) 57:1559-64. doi: 10.1016/j.biopsych.2005.02.025

30. Norrholm SD, Jovanovic T, Vervliet B, Myers KM, Davis M, Rothbaum BO, et al. Conditioned fear extinction and reinstatement in a human fear-potentiated startle paradigm. Learn Mem (2006) 13:681-5. doi: 10.1101/lm.393906

31. Glenn CR, Klein DN, Lissek S, Britton JC, Pine DS, Hajcak G. The development of fear learning and generalization in 8-13 year-olds. Dev Psychobiol (2012) 54:675-84. doi: $10.1002 /$ dev.20616

32. Myers KM, Ressler KJ, Davis M. Different mechanisms of fear extinction dependent on length of time since fear acquisition. Learn Mem (2006) 13:216-23. doi: 10.1101/lm.119806

33. Monfils MH, Cowansage KK, Klann E, Ledoux JE. Extinction-reconsolidation boundaries: key to persistent attenuation of fear memories. Science (2009) 324: 951-5. doi: 10.1126/science.1167975

34. Rescorla RA. Conditioned inhibition of fear resulting from negative CS-US contingencies. J Comp Physiol Psychol (1969) 67:504-9. doi: 10.1037/h0027313

35. Jovanovic T, Sakoman AJ, Kozaric-Kovacic D, Mestrovic AH, Duncan EJ, Davis M, et al. Acute stress disorder versus chronic posttraumatic stress disorder: inhibition of fear as a function of time since trauma. Depress Anxiety (2013) 30:217-24. doi: 10.1002/da.21991

36. Norrholm SD, Jovanovic T, Smith AK, Binder E, Klengel T, Conneely K, et al. Differential genetic and epigenetic regulation of catechol-O-methyltransferase is associated with impaired fear inhibition in posttraumatic stress disorder. Front Behav Neurosci (2013) 7:30. doi: 10.3389/fnbeh.2013.00030

37. Warren VT, Anderson KM, Kwon C, Bosshardt L, Jovanovic T, Bradley B, et al. Human fear extinction and return of fear using reconsolidation update mechanisms: the contribution of on-line expectancy ratings. Neurobiol Learn Mem (2013) 113:165-73. doi: 10.1016/j.nlm.2013.10.014

38. Rothbaum BO, Price M, Jovanovic T, Norrholm SD, Gerardi M, Dunlop B, et al. A randomized, double-blind evaluation of d-cycloserine or alprazolam combined with virtual reality exposure therapy for posttraumatic stress disorder in Iraq and Afghanistan War Veterans. Am J Psychiatry (2014) 171:640-8. doi: 10.1176/appi. ajp.2014.13121625

39. Jovanovic T, Ressler KJ. How the neurocircuitry and genetics of fear inhibition may inform our understanding of PTSD. Am J Psychiatry (2010) 167:648-62. doi: 10.1176/appi.ajp.2009.09071074 
40. Norrholm SD, Jovanovic T. Translational fear inhibition models as indices of trauma-related psychopathology. Curr Psychiatry Rev (2011) 7:194-204. doi: 10.2174/157340011797183193

41. Milad MR, Orr SP, Lasko NB, Chang Y, Rauch SL, Pitman RK. Presence and acquired origin of reduced recall for fear extinction in PTSD: results of a twin study. $J$ Psychiatr Res (2008) 42:515-20. doi: 10.1016/j.jpsychires.2008.01.017

42. Milad MR, Pitman RK, Ellis CB, Gold AL, Shin LM, Lasko NB, et al. Neurobiological basis of failure to recall extinction memory in posttraumatic stress disorder. Biol Psychiatry (2009) 66:1075-82. doi: 10.1016/j.biopsych.2009.06.026

43. Galatzer-Levy IR, Bonanno GA, Bush DE, Ledoux JE. Heterogeneity in threat extinction learning: substantive and methodological considerations for identifying individual difference in response to stress. Front Behav Neurosci (2013) 7:55. doi: 10.3389/fnbeh.2013.00055

44. Galatzer-Levy IR, Ankri Y, Freedman S, Israeli-Shalev Y, Roitman P, Gilad M, et al. Early PTSD symptom trajectories: persistence, recovery, and response to treatment: results from the Jerusalem Trauma Outreach and Prevention Study (J-TOPS). PLoS One (2013) 8:e70084. doi: 10.1371/journal.pone.0070084

45. Jovanovic T, Norrholm SD, Blanding NQ, Davis M, Duncan E, Bradley B, et al. Impaired fear inhibition is a biomarker of PTSD but not depression. Depress Anxiety (2010) 27:244-51. doi: 10.1002/da.20663

46. Bishop SJ. Neurocognitive mechanisms of anxiety: an integrative account. Trends Cogn Sci (2007) 11:307-16. doi: 10.1016/j.tics.2007.05.008

47. Fani N, Tone EB, Phifer J, Norrholm SD, Bradley B, Ressler KJ, et al. Attention bias toward threat is associated with exaggerated fear expression and impaired extinction in PTSD. Psychol Med (2012) 42:533-43. doi: 10.1017/S0033291711001565

48. Bokszczanin A. PTSD symptoms in children and adolescents 28 months after a flood: age and gender differences. J Trauma Stress (2007) 20:347-51. doi: 10.1002/ jts. 20220

49. Iwadare $\mathrm{Y}$, Usami M, Suzuki $\mathrm{Y}$, Ushijima H, Tanaka T, Watanabe $\mathrm{K}$, et al. Posttraumatic symptoms in elementary and junior high school children after the 2011 Japan earthquake and tsunami: symptom severity and recovery vary by age and sex. J Pediatr (2014) 164(917-921):e911. doi: 10.1016/j.jpeds.2013.11.061

50. True WR, Rice J, Eisen SA, Heath AC, Goldberg J, Lyons MJ, et al. A twin study of genetic and environmental contributions to liability for posttraumatic stress symptoms. Arch Gen Psychiatry (1993) 50:257-64. doi: 10.1001/ archpsyc. 1993.01820160019002

51. Binder EB, Bradley RG, Liu W, Epstein MP, Deveau TC, Mercer KB, et al. Association of FKBP5 polymorphisms and childhood abuse with risk of posttraumatic stress disorder symptoms in adults. JAMA (2008) 299:1291-305. doi: 10.1001/ jama.299.11.1291

52. Yehuda R, Bell A, Bierer LM, Schmeidler J. Maternal, not paternal, PTSD is related to increased risk for PTSD in offspring of Holocaust survivors. J Psychiatr Res (2008) 42:1104-11. doi: 10.1016/j.jpsychires.2008.01.002

53. Skelton K, Ressler KJ, Norrholm SD, Jovanovic T, Bradley-Davino B. PTSD and gene variants: new pathways and new thinking. Neuropharmacology (2012) 62:628-37. doi: 10.1016/j.neuropharm.2011.02.013

54. Almli LM, Fani N, Smith AK, Ressler KJ. Genetic approaches to understanding post-traumatic stress disorder. Int J Neuropsychopharmacol (2014) 17:355-70. doi: $10.1017 / S 1461145713001090$

55. Amstadter AB, Nugent NR, Koenen KC. Genetics of PTSD: fear conditioning as a model for future research. Psychiatr Ann (2009) 39:358-67. doi: 10.3928/00485713-20090526-01

56. Johnson LR, Mcguire J, Lazarus R, Palmer AA. Pavlovian fear memory circuits and phenotype models of PTSD. Neuropharmacology (2012) 62:638-46. doi: 10.1016/j. neuropharm.2011.07.004

57. Myers KM, Toufexis DJ, Winslow JT, Jovanovic T, Norrholm SD, Duncan E, et al. Measurement of fear inhibition in rats, monkeys, and humans with or without posttraumatic stress disorder, using the AX+, BX-paradigm. In: Whalen PJ, Phelps EA, editors. The Human Amygdala. New York, NY: The Guilford Press (2009). p. 61-81.

58. Norrholm SD, Anderson KM, Olin IW, Jovanovic T, Kwon C, Warren VT, et al. Versatility of fear-potentiated startle paradigms for assessing human conditioned fear extinction and return of fear. Front Behav Neurosci (2011) 5:77. doi: 10.3389/ fnbeh.2011.00077

59. Schiller D, Monfils MH, Raio CM, Johnson DC, Ledoux JE, Phelps EA. Preventing the return of fear in humans using reconsolidation update mechanisms. Nature (2010) 463:49-53. doi: 10.1038/nature08637

60. Sharp S, Thomas C, Rosenberg L, Rosenberg M, Meyer W III. Propranolol does not reduce risk for acute stress disorder in pediatric burn trauma. J Trauma (2010) 68:193-7. doi: 10.1097/TA.0b013e3181a8b326
61. Parsons RG, Ressler KJ. Implications of memory modulation for posttraumatic stress and fear disorders. Nat Neurosci (2013) 16:146-53. doi: $10.1038 / \mathrm{nn} .3296$

62. Holbrook TL, Galarneau MR, Dye JL, Quinn K, Dougherty AL. Morphine use after combat injury in Iraq and post-traumatic stress disorder. NEngl J Med (2010) 362:110-7. doi: 10.1056/NEJMoa0903326

63. Falls WA, Miserendino MJ, Davis M. Extinction of fear-potentiated startle: blockade by infusion of an NMDA antagonist into the amygdala. J Neurosci (1992) 12:854-63.

64. Walker DL, Ressler KJ, Lu KT, Davis M. Facilitation of conditioned fear extinction by systemic administration or intra-amygdala infusions of D-cycloserine as assessed with fear-potentiated startle in rats. J Neurosci (2002) 22:2343-51.

65. Richardson R, Ledgerwood L, Cranney J. Facilitation of fear extinction by D-cycloserine: theoretical and clinical implications. Learn Mem (2004) 11:510-6. doi: $10.1101 / \mathrm{lm} .78204$

66. Guastella AJ, Lovibond PF, Dadds MR, Mitchell P, Richardson R. A randomized controlled trial of the effect of $\mathrm{D}$-cycloserine on extinction and fear conditioning in humans. Behav Res Ther (2007) 45:663-72. doi: 10.1016/j.brat.2006.07.005

67. Ressler KJ, Rothbaum BO, Tannenbaum L, Anderson P, Graap K, Zimand E, et al. Cognitive enhancers as adjuncts to psychotherapy: use of D-cycloserine in phobic individuals to facilitate extinction of fear. Arch Gen Psychiatry (2004) 61:1136-44. doi: 10.1001/archpsyc.61.11.1136

68. Otto MW, Mchugh RK, Simon NM, Farach FJ, Worthington JJ, Pollack MH. Efficacy of CBT for benzodiazepine discontinuation in patients with panic disorder: further evaluation. Behav Res Ther (2010) 48:720-7. doi: 10.1016/j.brat.2010.04.002

69. Hofmann SG, Meuret AE, Smits JA, Simon NM, Pollack MH, Eisenmenger K, et al. Augmentation of exposure therapy with D-cycloserine for social anxiety disorder. Arch Gen Psychiatry (2006) 63:298-304. doi: 10.1001/archpsyc.63.3.298

70. Hofmann SG, Smits JA, Rosenfield D, Simon N, Otto MW, Meuret AE, et al. d-Cycloserine as an augmentation strategy with cognitive-behavioral therapy for social anxiety disorder. Am J Psychiatry (2013) 170:751-8. doi: 10.1176/appi. ajp.2013.12070974

71. Kushner MG, Kim SW, Donahue C, Thuras P, Adson D, Kotlyar M, et al. $\mathrm{D}$-cycloserine augmented exposure therapy for obsessive-compulsive disorder. Biol Psychiatry (2007) 62:835-8. doi: 10.1016/j.biopsych.2006.12.020

72. Wilhelm S, Buhlmann U, Tolin DF, Meunier SA, Pearlson GD, Reese HE, et al. Augmentation of behavior therapy with D-cycloserine for obsessive-compulsive disorder. Am J Psychiatry (2008) 165:335-41; quiz 409. doi: 10.1176/appi. ajp.2007.07050776

73. Chasson GS, Buhlmann U, Tolin DF, Rao SR, Reese HE, Rowley T, et al. Need for speed: evaluating slopes of OCD recovery in behavior therapy enhanced with d-cycloserine. Behav Res Ther (2010) 48:675-9. doi: 10.1016/j. brat.2010.03.007

74. de Kleine RA, Hendriks GJ, Kusters WJ, Broekman TG, Van Minnen A. A randomized placebo-controlled trial of D-cycloserine to enhance exposure therapy for posttraumatic stress disorder. Biol Psychiatry (2012) 71:962-8. doi: 10.1016/j. biopsych.2012.02.033

75. Litz BT, Salters-Pedneault K, Steenkamp MM, Hermos JA, Bryant RA, Otto MW, et al. A randomized placebo-controlled trial of D-cycloserine and exposure therapy for posttraumatic stress disorder. J Psychiatr Res (2012) 46:1184-90. doi: 10.1016/j. jpsychires.2012.05.006

76. Hofmann SG, Wu JQ, Boettcher H. d-Cycloserine as an augmentation strategy for cognitive behavioral therapy of anxiety disorders. Biol Mood Anxiety Disord (2013) 3:11. doi: 10.1186/2045-5380-3-11

77. Smits JA, Rosenfield D, Otto MW, Powers MB, Hofmann SG, Telch MJ, et al. D-cycloserine enhancement of fear extinction is specific to successful exposure sessions: evidence from the treatment of height phobia. Biol Psychiatry (2013) 73:1054-8. doi: 10.1016/j.biopsych.2012.12.009

78. Difede J, Cukor J, Wyka K, Olden M, Hoffman H, Lee FS, et al. D-cycloserine augmentation of exposure therapy for post-traumatic stress disorder: a pilot randomized clinical trial. Neuropsychopharmacology (2014) 39:1052-8. doi: 10.1038/ npp. 2013.317

79. Karpova NN, Pickenhagen A, Lindholm J, Tiraboschi E, Kulesskaya N, Agustsdottir A, et al. Fear erasure in mice requires synergy between antidepressant drugs and extinction training. Science (2011) 334:1731-4. doi: 10.1126/ science. 1214592

80. Yang CH, Shi HS, Zhu WL, Wu P, Sun LL, Si JJ, et al. Venlafaxine facilitates betweensession extinction and prevents reinstatement of auditory-cue conditioned fear. Behav Brain Res (2012) 230:268-73. doi: 10.1016/j.bbr.2012.02.023 
81. Deschaux O, Zheng X, Lavigne J, Nachon O, Cleren C, Moreau JL, et al. Postextinction fluoxetine treatment prevents stress-induced reemergence of extinguished fear. Psychopharmacology (Berl) (2013) 225:209-16. doi: 10.1007/ s00213-012-2806-x

82. Bui E, Orr SP, Jacoby RJ, Keshaviah A, Leblanc NJ, Milad MR, et al. Two weeks of pretreatment with escitalopram facilitates extinction learning in healthy individuals. Hum Psychopharmacol (2013) 28:447-56. doi: 10.1002/hup.2330

83. Chhatwal JP, Davis M, Maguschak KA, Ressler KJ. Enhancing cannabinoid neurotransmission augments the extinction of conditioned fear. Neuropsychopharmacology (2005) 30:516-24. doi: 10.1038/sj.npp.1300655

84. Gunduz-Cinar O, Hill MN, Mcewen BS, Holmes A. Amygdala FAAH and anandamide: mediating protection and recovery from stress. Trends Pharmacol Sci(2013) 34:637-44. doi: 10.1016/j.tips.2013.08.008

85. Gunduz-Cinar O, Macpherson KP, Cinar R, Gamble-George J, Sugden K, Williams $\mathrm{B}$, et al. Convergent translational evidence of a role for anandamide in amygdalamediated fear extinction, threat processing and stress-reactivity. Mol Psychiatry (2013) 18:813-23. doi: 10.1038/mp.2012.72

86. Acheson D, Feifel D, De Wilde S, Mckinney R, Lohr J, Risbrough V. The effect of intranasal oxytocin treatment on conditioned fear extinction and recall in a healthy human sample. Psychopharmacology (Berl) (2013) 229:199-208. doi: 10.1007/ s00213-013-3099-4

87. Marvar PJ, Goodman J, Fuchs S, Choi DC, Banerjee S, Ressler KJ. Angiotensin type 1 receptor inhibition enhances the extinction of fear memory. Biol Psychiatry (2014) 75:864-72. doi: 10.1016/j.biopsych.2013.08.024

88. Maren S, Chang CH. Recent fear is resistant to extinction. Proc Natl Acad Sci U S A (2006) 103:18020-5. doi: 10.1073/pnas.0608398103

89. Woods AM, Bouton ME. Immediate extinction causes a less durable loss of performance than delayed extinction following either fear or appetitive conditioning. Learn Mem (2008) 15:909-20. doi: 10.1101/lm.1078508

90. Norrholm SD, Vervliet B, Jovanovic T, Boshoven W, Myers KM, Davis M, et al. Timing of extinction relative to acquisition: a parametric analysis of fear extinction in humans. Behav Neurosci (2008) 122:1016-30. doi: 10.1037/a0012604
91. Golkar A, Bellander M, Olsson A, Ohman A. Are fear memories erasable?-reconsolidation of learned fear with fear-relevant and fear-irrelevant stimuli. Front Behav Neurosci (2012) 6:80. doi: 10.3389/fnbeh.2012.00080

92. Oyarzun JP, Lopez-Barroso D, Fuentemilla L, Cucurell D, Pedraza C, RodriguezFornells A, et al. Updating fearful memories with extinction training during reconsolidation: a human study using auditory aversive stimuli. PLoS One (2012) 7:e38849. doi: 10.1371/journal.pone.0038849

93. Kindt $M$, Soeter M. Reconsolidation in a human fear conditioning study: a test of extinction as updating mechanism. Biol Psychol (2013) 92:43-50. doi: 10.1016/j. biopsycho.2011.09.016

94. Breslau N, Davis GC, Andreski P, Peterson EL, Schultz LR. Sex differences in posttraumatic stress disorder. Arch Gen Psychiatry (1997) 54:1044-8. doi: 10.1001/ archpsyc.1997.01830230082012

95. Ressler KJ, Mercer KB, Bradley B, Jovanovic T, Mahan A, Kerley K, et al. Posttraumatic stress disorder is associated with PACAP and the PAC1 receptor. Nature (2011) 470:492-7. doi: 10.1038/nature09856

Conflict of Interest Statement: The authors declare that the research was conducted in the absence of any commercial or financial relationships that could be construed as a potential conflict of interest.

Received: 21 May 2014; accepted: 08 July 2014; published online: 21 July 2014.

Citation: Briscione MA, Jovanovic T and Norrholm SD (2014) Conditioned fear associated phenotypes as robust, translational indices of trauma-, stressor-, and anxiety-related behaviors. Front. Psychiatry 5:88. doi:10.3389/fpsyt.2014.00088

This article was submitted to the journal Frontiers in Psychiatry.

Copyright (C) 2014 Briscione, Jovanovic and Norrholm. This is an open-access article distributed under the terms of the Creative Commons Attribution License (CC BY). The use, distribution or reproduction in other forums is permitted, provided the original author(s) or licensor are credited and that the original publication in this journal is cited, in accordance with accepted academic practice. No use, distribution or reproduction is permitted which does not comply with these terms. 